\title{
Comments on the paper "Medicolegal implications of accuracy of GP referral letters to specialist breast clinic"
}

\author{
D. Murray ${ }^{1}$
}

Received: 4 March 2015/Accepted: 29 March 2015/Published online: 7 April 2015

(C) Royal Academy of Medicine in Ireland 2015

\begin{abstract}
Ahmed and colleagues [1] have described well the dilemmas faced by clinicians when diagnosing women with symptomatic breast disease. However, one important factor was omitted that helps to explain the poor correlation between general practitioner findings and those assigned by the specialist in the breast clinic. The positive predictive value of symptoms, signs and non-diagnostic test results (that is, the likelihood that a patient who tests positive actually has the disease) varies strongly with disease prevalence $[2,3]$. The same test with the same sensitivity and specificity will have more false positives in a lower disease prevalence setting (e.g. primary care) than in a higher disease prevalence setting (e.g. hospital) $[4,5]$. Thus, a clinician with a certain standard of skills in clinical history taking and clinical examination, if working in primary care, will have more false positives than the same clinician working in a hospital setting.
\end{abstract}

\section{References}

1. Ahmed A, Marginan A, Sweeney K et al (2014) Medicolegal implications of accuracy of GP referral letters to specialist breast clinic. Ir J Med Sci. doi:10.1007/s11845-014-1223-z

2. Brenner H, Gefeller O (1997) Variation of sensitivity, specificity, likelihood ratios and predictive values with disease prevalence. Stat Med 16(9):981-991

3. Last JM (2001) A dictionary of epidemiology. Oxford University Press, New York

4. Shapley M, Mansell G, Jordan JL et al (2010) Positive predictive values of $\geq 5 \%$ in primary care for cancer: systematic review. $\mathrm{Br} \mathrm{J}$ Gen Pract 60(578):e366-e377. doi:10.3399/bjgp10X515412

5. Gray M (2009) Evidence based healthcare and public health. Churchill Livingstone, Elsevier
D. Murray

DeirdreE.Murray@hse.ie

1 National Cancer Control Programme, Health Service Executive, Cork, Ireland 